Huw Macartney and Stuart Shields

\title{
Finding space in IPE
}

This chapter focuses predominantly on the treatment of the international as a space within International Political Economy (IPE). This edited volume highlights, albeit often implicitly, two areas of concern within IPE. Many of the chapters tend to focus on the relationship between the political and the economic, for example in addressing the relationship between IPE and International Relations (IR). We argue that where the relationship between the political and economic has been the primary focus of debate within the discipline, the analogous question of the relationship between different spaces has been anything but clear. We further argue that in spite of numerous attempts to overcome it, the national-international dichotomy continues to permeate too much of contemporary IPE. We see this as somewhat ironic, given that critical IPE has deliberately positioned itself in opposition to orthodox IPE precisely because of the orthodoxy's failure to capture the social content or underlying power structures of global capitalism (Bieler and Morton,

AQ1 2008). This is most obvious in those attempts that analyse the historical and social but only include space as a nodal point for analysis of the political agency of capital (compare Morton, 2007; Underhill, 2003). In contrast we argue that a more nuanced understanding of space as one constitutive element of capitalism is central to the notions of emancipation and resistance which are at the heart of a critical IPE project. We achieve this by exploring a scalar-relational approach to critical IPE that develops a more differentiated view of spatialization in the global economy. 
To substantiate this we draw on work within political geography and the notion of scale as a relational approach to the question of space. Rather than reifying particular spatial forms at a specific scale, our analysis focuses on the process of scaling, that is, 'the production, reconfiguration or contestation of particular differentiations, orderings and hierarchies among [different] scales' (Brenner, 2001, p. 600). The chapter unfolds in three substantive sections. First, we examine so-called orthodox IPE and the question of space. Here we claim that the state-centric assumptions inherent to such accounts provide limitations which culminate in a move from an ostensibly Westphalian form of nationalism to internationalization and an overtly stratified conception of a levels-of-analysis approach. Second, the chapter examines critical IPE and extant notions of space. Here, many initial accounts bear striking similarities to the laminated internationalization evidenced in the orthodoxy. More recent accounts suggest the transnational as a potentially fruitful alternative. This concept is frequently invoked, yet remains problematically deployed, often giving way to a nodal conception of the transnational as simply another platform, another laminate, for social relations. Finally, we move to contend that the production of space and scale itself, rather than just the scales between spaces, is both constituent and outcome of these social relations. Put differently, space and scale are internal to capitalism rather than epiphenomenal. In the concluding section we propound an alternative reading of the transnational and suggest that this might be a useful contribution to the counter-hegemonic project at the heart of critical IPE.

\section{Orthodox IPE: from the national to the international to the global}

\section{Realism to neoliberalism}

As we begin to outline the problem of space, we explore how IPE has tended to 'add-space-and-mix' to its analytical focus on the political and the economic. The myth is maintained that IPE emerged because of its focus on global phenomena, the spread of financial and production networks, the rise of international and intergovernmental institutions, the proliferation of technologies and communications, and social movements transcending national boundaries, engendering both quantitative and qualitative change in world history. This particular myth supports and reinforces the notion that IPE is a sub-discipline of IR that emerged as a response to the global restructuring of capitalism 


\section{PROOF}

Huw Macartney and Stuart Shields

in the 1970s (Murphy and Tooze, 1991; Strange, 1996). ${ }^{1}$ Orthodox IPE originates in realist and liberal categories of analysis constituted around the idea of hegemonic stability and associated theory.

Where neo-realism provides by far the clearest and most selfconscious example of rationalist assumptions that the international system is determined by the coagulation of national economies and nationally based preferences, neoliberalism articulates a structurally similar approach. The key difference is over the content of preferences referring to, for example, economic versus military power, and absolute versus relative gains. States-as-actors and the inter-national system are self-evidently axiomatic. These earliest accounts struggled, however, to conceptualize the interrelationship between the national and the so-called international.

To assert the international simply as the overflow of the national ignored important effects that the international had on shaping state preferences in an interdependent world. Robert Putnam's two-level game metaphor was an attempt within liberal theory to explain how political entrepreneurs bring the influence of the international to their national-domestic politics whilst, simultaneously, the politics emerging domestically, in turn, shape international positions (1988). Throughout this period in the development of IPE, there was an effort to theorize the changes taking place in the international system, while the key unitary actors, with determinant decision-making capabilities, remained nation states (Keohane, 1988, pp. 379-96). In spite of their interconnectedness, the domestic and international were relatively independently constituted, with the latter overdetermined by the former (ibid., p. 242).

From here, orthodox accounts began to develop the notion of internationalization as the product of the increasing openness of national economies. This reproduced a separately constituted yet interconnected approach, meaning that to understand politics within countries an analysis of the nature of the linkages was required (Keohane and Milner, 1996, p. 3). Internationalization created both opportunities and constraints upon actors, which affected their policy preferences since it equated to the growth of international economic flows relative to domestic ones (ibid., p. 4). Not only are the underlying assumptions firmly rooted within the state-centric notion of national geographic territories as the key units of analysis, but the international - at least in so far as the focus of their analysis suggests - equates to the flows of investment, trade and actors that originate and therefore emerge out of the domestic; the nation state remains the container out of which the international emerges. 


\section{Global governance}

More recently, a useful example of the ongoing difficulties in addressing the question of the international as a space is highlighted by the burgeoning literature on global governance. It is ironic, though, how the global governance literature acknowledges the heterogeneity of knowledge, organizations and institutions in the global political economy but produces a generic image of the global governance scale-related qualities. These accounts are significant not simply because of their conception of space, but because in many ways they provide a point of departure for the critique provided by critical IPE. Competing conceptions of space are important to the development of IPE but remain a secondary concern to the emphasis on the political and economic relations of most accounts. We suggest an alternative starting point which sees the political, economic and spatial as initially and continually mutually constitutive to the production and reproduction of social relations.

Two broad perspectives to theorizing global governance have emerged to dominate the IPE literature: a complexity approach and a form of descriptive institutionalism. The defining feature of the former is its emphasis on the complexity of globalized processes. This presents an account that aims to provide the most epistemologically parsimonious analysis of the world in the pursuit of prediction and generalizable propositions. For James Rosenau, the complexity of emerging processes under globalization pre-empts an emphasis on technology as the determining factor (Rosenau, 1995) behind social change in keeping with the contemporary liberal IPE (Strange, 1996; Cerny, 1997). In addition, it is worth noting Cerny's journey which traverses the terrain of 'globalization' from a procumbent competition state to a labyrinthine transnational neopluralism (2010). The concentration on a series of connected but bounded spaces responding to the imperatives of competitiveness articulates a binary worldview that replicates a perspective driven by an 'in here' as distinct from a global 'out there'. From such foundations, complexity approaches proceed to examine the implications of the emergence of diverse actors such as the World Economic Forum, the European and World Social Forum, private groups like the International Chamber of Commerce and Non-Governmental Organizations (NGOs) in the micromanagement of political economic and social problems at competing and/or overlapping levels.

The crucial step, however, lies in the reproduction of the myth of a Westphalian topography in an international political economy, characterized by sovereign order (governance) imposed by the nation 


\section{PROOF}

state (Rosenau, 1995, p. 48). On this reading the globalization era evokes a 'relocation of authority in a shrinking world' (Rosenau, 1992). Two key difficulties can be discerned: one relates to the not unproblematic assumption of the parallelism and coincidence of sovereignty and distinct nation states; the other relates to the social struggles and antagonisms concealed by positing the locus of change in a technological determinacy. Put differently, it is our contention that such complexity explanations obfuscate the continuities between so-called post-war and globalization periods.

For critical IPE, these criticisms have been equated with an absence of an underlying social content. In effect, complexity theory adequately highlights the formal transformations without embedding them within an analysis of the causal social and spatial relations (van Apeldoorn, 2002, p. 12). As a result, complexity approaches highlight the 'powerful tensions, profound contradictions and perplexing paradoxes' that refer to little more than the

formal institutions and organisations through which the management of international affairs is or is not sustained; this includes systems of rule at all levels of human activity... [encompassing] the activities of governments, [and] many other channels through which commands flow in the form of goals framed, directives issued, and policy pursued.

(Rosenau, 1995, pp. 45-6)

To (re-)emphasize, the complexity and interdependence of contemporary social reality mystifies as much as it reveals, providing a misleading account of what has changed and then failing to address the social relations that explain why these spatial transformations take place.

A second series of accounts of global governance has emerged which implicitly rejects the insights of the complexity approach. Here, the focus is on a microanalysis of key agents within the institutions of global governance. In spite of the rich empirical detail, by avoiding the simplifying assumptions and regularities of an overtly rationalist institutionalism, what we term descriptive institutionalism fails to critically reflect on unacknowledged theoretical assumptions concerning, inter alia, the function of prevailing institutions in the production and reproduction of capitalist social relations on a global scale. In particular, we are concerned with the distinct lack of theorization of the social and political context within which the emergent forms of global governance occur. This creates a different, yet equally serious, problem from 
that of complexity approaches, namely that it obscures the political through a presentation of 'extra'-national processes as objective phenomena. Descriptive institutionalism is therefore based on an uncritical institutionalist account of the events, processes and, in particular, the institutions of global governance. As a result, whilst 'multilateral agreements on investment, government procurement, trade facilitation, and competition policy' (Wilkinson, 2004, p. 149) do not occur within a vacuum, historical, social and spatial conditions are treated as merely inputs and/or outputs to the political process under scrutiny.

There is an unhealthy predilection for seeing the international realm, especially in terms of its spatial dimension, as unchanging; in other words, as somehow existing outside of history (Lawson, 2007). By fixating on a particular starting period, more often than not post-1945 institutional development and policy process, descriptive institutionalism effectively freezes history, relegating its explanatory power to that of epiphenomenon. A more convincing account might be developed from a perspective that shifts the focus from the institutions of global governance as a set of bounded spaces to a scalar-relational perspective. This would contrast with the static picture of the structure of world politics wherein sovereign states exist axiomatically; unit level differences between international organizations are accepted unproblematically; encompassing forces such as global capitalism are omitted; and agency is reduced to the musings of statesmen, financiers, generals and international bureaucrats. By failing explicitly and reflexively to examine these elements, such descriptive institutionalism, despite claims to the contrary, assumes these musings to be timeless and constitutive of ahistorical structures.

This reduces global governance to the politics of novelty whereby a purportedly critical approach becomes a variation on the common themes developed by orthodox scholars, albeit with the extrinsic addition of an emancipatory rhetoric aimed at fostering the illusion of progressive social change (Bonefeld, 1998). The descriptive institutionalist literature remains inspired, directly or indirectly, by a set of basic notions germane to identifying the most effective management of economic performance in a global economy. Should our loftiest ambition really be the amelioration of the worst excesses of capitalism? The theoretical and political priority, therefore, never resides in a particular space or scale, but 'in the processes through which particular scales become (re)constituted' as unproblematic, neutral, objective and natural parts of the global political economy (Swyngedouw, 2004, p. 6). Our goal in briefly exploring these orthodox accounts is simply to highlight the 


\section{PROOF}

immanence of what we call the problem of space, which, as we shall see, has also plagued critical IPE.

\section{Critical IPE: from the international to the transnational}

\section{Cox and internationalization}

As other contributors to this volume have noted (see chapters by Worth and Ashworth), critical IPE owes an intellectual debt to the work of Robert Cox in at least two respects: first, in his characterization of critical theory as emancipatory theory predicated on the deconstruction of existing institutions and power configurations (1981), and second, because of his re-engagement with the work of Antonio Gramsci. Both of these interventions have meant that the criteria of assessment for critical IPE have been an attempt to disclose the underlying and reified social relations and to embed them within a particular theory of historical change (Bieler and Morton, 2001; van Apeldoorn, 2004, p. 145). Ironically, then, we argue that the intended goal of critical IPE in its normative and emancipatory agenda is undermined by the secondary and epiphenomenal status accorded to the production and reproduction of space within its accounts.

As noted above, there are certain similarities between the starting premises of Cox's analysis and those of more orthodox liberal institutionalism. For Cox, globalization was an elite-driven process, with states once again shaped in their preferences and outlooks by their particular position within these wider global processes. As a result, particular state apparatuses acted as mediators between the global restructuring of capitalism and the spheres of finance and production most closely linked to these exogenous changes. The interests of national social forces were therefore subordinated to the demands of the global economy. The nébuleuse of both formal and informal international institutions therefore emerges to connect major capitalist states, with particular neoliberal ideology and discourse acting as a political rationalization of these nascent configurations (Cox, 1995, p. 30).

Stephen Gill sought to explain the liberalized and commodified historical structures driven by the restructuring of capital which characterizes contemporary world order. Central to his account is the 'spatial expansion and social deepening' of particular definitions of social enterprise and individualistic politics (1995, p. 399). Put differently, Gill notes that accumulation, legitimation, consumption and work carry with them expansionary tendencies, important to these 
wider transformations and, in particular, contribute to the emergence of a historical bloc. This bloc comprises local political structures as well as constituting a global political and civil society (ibid., p. 400). As a result, it is a neoliberal/transnational historical bloc existing within and across nations and forms the analytical core of his work.

This conception of space is perhaps most apparent though in Gill's discussions of the structural power of transnational capital, operating within this bloc (ibid., pp. 430, 407). By transnational capital Gill means transnational firms, operating across multiple jurisdictions. The structural power of capital is dependent upon the reduction in barriers to the international mobility of capital, and the constraints and incentive structures that this imposes upon national states (Gill and Law, 1989, p. 478). So the analysis targets the power of those fractions of capital that are both large in scope and internationally mobile. Further, the global character of these power relations is taken as self-evident, given the rise of transnational corporations and degree of international capital mobility (ibid., p. 482). ${ }^{2}$ Again, despite protestations to the contrary, the social and the historical are privileged, whilst space is stratified as a platform for these relations.

Already, we begin to perceive the difficulties this raises for the normative project of critical IPE. The tendency here is to present a relatively homogenous transnational elite as the key agent of 'globalization'. This is only reinforced by the relatively autonomous partitioning of the transnational from the local or national (Gill, 1995, p. 411; see also Gill, 2008, p. 59). Precisely in seeking to avoid this tendency embedded within a state-centric approach, Gill and Law (1989) proffer social forces as new and alternative agents. This only reinforces the difficulty however, given the repeated recourse to other defunct remnants of orthodox IPE; remnants such as the 'global level' (ibid., p. 476). Put differently, space is unproblematically assumed to exist a priori, such that - as national governments remove barriers - this pre-existing space is available for newly liberated capital (ibid., pp. 479-81). Capital relocates from one country to another, depending on legal freedoms, production costs, labour relations, political stability and financial concessions, so that transnational capital is defined as internationally mobile capital, subsequently imposing structural power over states themselves (ibid., p. 484). The circularity of the argument can be appreciated through an understanding of the spatial.

The difficulty with this conception is also apparent at times in the work of the Amsterdam School. The central objective of these accounts has been to develop a more nuanced understanding of the relationship 


\section{PROOF}

between the dynamics of capital accumulation and the formation of hegemonic ideas (Overbeek, 2000). Once again there has been a specific attempt to engage with the IR concepts employed by orthodox IPE (see above). Significantly, these accounts depart from the more straightforward Gramscian reading, which usually starts with Cox's work as the key interlocutor. Instead, the Amsterdam School begins most emphatically with Marx and Poulantzas rather than Cox or Gramsci (Overbeek, 2004). In contrast to the liberal and actor-centred perspectives of orthodox IPE, this emphasizes the importance of transnational (economic) structures, whilst reasserting the centrality of class agency. IR is perceived as being inter-national, whereas transnational historical materialism argues that these particular relations are inextricably bound up within an expanding capitalist world economy and transnational social relations (van Apeldoorn, 2004, p. 143). The key contribution of this position is the process of transnational class formation and, in our view, it is here that the underlying difficulty of this spatial characterization has significant political implications for critical IPE.

To understand transnational relations - a central prerogative of the Amsterdam project - 'the transnational' itself is depicted as a phenomenon as opposed to a level (ibid.,p. 144). Though this conceptualization avoids the difficulties, on the one hand, of a levels of analysis approach comprised of national, international and/or global, and, on the other hand, a notion of the transnational as completely distinct and separate from national spaces (whatever this might mean), it infers, however, that these actors operate within several national contexts simultaneously (ibid., p. 145). Defining the transnational relies on recourse to the national as the determining frame of reference. From this point of inception, an analysis that privileges the agency of particular social forces unfolds, albeit within the context of economic relations characterized as global capitalism. The idea of space itself is not constituted in and through, inter alia, class struggle, only the ability to operate within it. A predetermined space already exists; social forces struggle over access to it. For the Amsterdam project, these social relations were therefore always at least partially transnational in nature; it is simply that they have become more extensive and deeply embedded in the contemporary world order. As Overbeek and van der Pijl note, one of the crucial dimensions of change in the historical process of capitalist development is capital's paradigmatic scale of operation, referring to the spatial dimensions of the process, in particular the widening scale of operation of productive capital, from local in the early capitalist period to national in the nineteenth century, to Atlantic in the mid-twentieth 
century, and to global in the early twenty-first century (Overbeek and van der Pijl, 1993; Arrighi, 2005a, 2005b).

Similar concerns also emerge within neo-Gramscian perspectives and their focus on the political agency of capital (Morton, 2007). These approaches have, in many ways, been central to the reinvigoration of historical materialist analysis within IPE. Their dominant characteristics are the critical normative position and analysis of class struggle as a heuristic device for understanding the global restructuring of capitalism; in this respect they are the logical descendants of Cox's analysis outlined above. Their core contribution has been an examination of forms of cultural and moral leadership mediated through an extensive range of social institutions and organizations in understanding class hegemony in the contemporary world order.

With this particular focus in mind, there has been a growing appreciation of the complexity of the spatial relations of global capitalism which simply cannot be captured by a levels of analysis approach. In its initial instantiation, transnationalization was referred to as the 'material' reorganization of production and finance within and across nation states (Bieler and Morton, 2001, p. 4; Cox, 1993, pp. 259-260). More recently, there have been attempts to conceptualize the multiscalarity of capitalism, such that it does not simply supplant one spatial scale for another but instead works across spatial scales located within state forms and geopolitics (Morton, 2007). Thus the transnational does not replace the national, nor do social forces operating on one scale lose touch with other scales, since capitalism operates at nodal rather than dominant points. In substantive terms however, the agency question that drives neo-Gramscian perspectives gives rise to a similar risk as encountered within the Amsterdam project: capitalism is multiscalar, but its key actors operate across and within these particular nodal points, thereby vying for access to pre-constituted social space. As a result, hegemony can operate at two levels, within a form of state as well as by expanding a mode of production internationally projecting through the level of world order (Bieler and Morton, 2004, p. 93). Though this avoids the zerosum games of orthodox accounts, it continues to imply a binary logic that provides a problematic conceptualization of the relations between particular scales and the constitution of space. Instead, this essentializes the meaning of spatial relations in IPE as almost reducible to the national/international, with these spaces somehow bearing certain autonomous effects.

To recap, we began with the premise that an accurate understanding of the historical and social characteristics of the international political 


\section{PROOF}

economy requires a conceptualization of space. Three key criticisms have therefore been raised. First, that within orthodox accounts of IPE a levels of analysis approach continues to reside, building upon the assumptions of IPE as a sub-discipline to IR; elsewhere, less explicit but equally unsatisfactory alternatives are provided by accounts of technological determinacy and thick descriptive institutionalism. Second, historical materialist-inspired readings within critical IPE offer a more nuanced account in their rendering of social space as a site for class struggle. Yet it is precisely through starting with the social - be it in the form of relations of production and/or hegemony - that the spatial becomes a platform for the all-important object of analysis. Third, therefore, we suggest that to examine the historical and the social, the mutually constitutive internal relations of the spatial are also required from the outset. The following section therefore addresses this concern, before focusing more explicitly on the politics of scale and its implications for critical IPE.

\section{Towards a scalar-relational account of critical IPE}

The above sections ought to have revealed the preoccupation of critical IPE with questions of resistance and emancipation, rooted in a critical normative position. Our concern in the following section is therefore twofold: we argue that an appreciation of the social content and relations of (historical) processes of change requires a nuanced conception of scale and space. To de-reify asymmetrical power relations, different spaces and scales of capitalism either lend themselves to the coherence and unity of dominant agents or suggest potential political openings for reform and change. There are different levels of 'where' capital can operate most efficiently and the transnational indicates the relationship between scales, not a zero-sum game but relational processes that can as easily be in contradiction and competition with one another, as they are complementary. We return to this below.

For now, our focus remains on the structures and agents at work within the processes of neoliberalization, as a particular example of how spatial matters concern us (Peck and Tickell, 2002, p. 993). We understand neoliberalism as an attempt to restore stable patterns of accumulation through the reconfiguration of political-economic institutions on multiple, competing and yet overlapping scales (Peck and Tickell, 2002). First, however, to contextualize our discussion of the IPE of scale it is necessary to understand the spatial. Rejecting an encompassing determinism we nonetheless argue that the production, reproduction 
and reconstitution of space are inherent to the material and ideological representations of class struggle and contradiction central to the global restructuring of capitalism. This requires a move from separate, independently constituted and therefore externally related components, to mutually constitutive, internally related units of a dialectical totality comprised of the social, the historical and the spatial.

At an abstract level, historical materialism has long noted the internal propensity of capitalism to engender the creative destruction of space and spatial configurations. On the one hand, capital, in its insatiable drive to secure new investment opportunities and realize greater profits, is inherently oriented towards the elimination of barriers to the circulation process (Marx, 1973[1857], p. 539). On the other hand, the continued temporal acceleration of capital circulation is predicated upon the production of space and spatial configurations (Harvey, 1985, p. 145). Complex matrices of transport, communications and regulatory institutional infrastructures therefore emerge to facilitate a reduction in the socially average turnover time of capital (Brenner, 1998, p. 433). The production, destruction and reconstruction of these spatial configurations are therefore immanent to capitalism itself and the reproduction of capitalist social relations.

This departs from the add-space-and-mix conception of critical IPE. As Brenner notes (1999b, p. 40), '[u]nder these circumstances, space no longer appears as a static platform of social relations, but rather as one of their constitutive dimensions, itself historically produced, reconfigured and transformed'. Much as critical IPE has been at pains to emphasize the internal relations of the political and economic, such that the state can be seen as an alternative form of the same social relations as the market, the spatial element captured by the 'international' of the acronym IPE cannot be reduced to a platform or container of social relations and class struggle. Instead, space is bound within politicaleconomic relations and, simultaneously, a product thereof. Space and scale are neither ontologically given nor politically and discursively neutral; space and scale embody power relations. The social constitution of space is therefore already imbricated in assumptions of class and gender which themselves must be elucidated as part of the project of critical IPE. Without precluding a particular entry point, this understanding of space requires a departure from the tendency towards a zero-sum analysis of the national and/or international. Swyngedouw suggests that 'starting analysis from a given geographical scale, such as the local, regional, national, or global, seems ... to be deeply antagonistic to apprehending the world' (2004, p. 26). We would argue that 


\section{PROOF}

such an entry point is inevitable and necessary in order for anything meaningful to be said about the power relations and the distribution of wealth in the global economy, but that closer attention needs to be paid to the relations between these various scales in a way that avoids the nodal points of critical IPE. Put differently, actors and processes do not simply pass in and out of focus at the national and then reappear at the international (or indeed transnational) scale, since the two remain not just connected but mutually constitutive and codependent (Shields, 2008, 2011; Macartney, 2010). The relationship is not of discrete scales and spaces, a series of neat boxes with neatly regularized attributes and processes. Territorial dependencies remain, but such dependencies are neither absolute nor deterministic.

For example then, though the foundational principles of neoliberal ideology posit economic and developmental beneficence in open, competitive markets via utility maximizing individual citizens, the application of such neoliberal strategies produces not simply markets - as organizational forms of collective rationality - but new institutional and regulatory landscapes with their own functional logics and political imperatives (Peck and Tickell, 2002). To freeze and therefore marginalize, or to separate as distinct, particular components of this complex and dynamic totality, overlooks how these processes are coterminous and codependent rather than autonomous (see, for example, McMichael, 1990). These processes cannot be understood in the singular since 'interrelated instances are integral to, and define, the general historical process' (ibid., p. 389). To fail to do so is tantamount to focusing on diverse historical processes through which a particular spatial form is established as a 'differentiated unit of socio spatial organization, activity, conflict, struggle, discourse and/or imagination' (Brenner, 2001, p. 599).

To put it more bluntly, if we assume there to be national and transnational spaces then we risk homogenizing actors and processes that are not strictly contained within particular geographical parameters. Spatial forms are thus endowed with scale-specific qualities that define their position against other spatial forms. For example, social forces without links beyond their particular nation state are national, whilst social forces with operations in several national territories are transnational. The important idiosyncrasies of these agents are lost in the attempt to determine collective forms of agency. Instead, these historical, spatial and scalar social relations simultaneously encompass different territorial levels in a multilevel conception which can also accommodate non-territorial phenomena (Anderson, 2002, p. 16). In 
what follows we briefly outline an alternative approach which, in our view, overcomes these difficulties.

This alternative approach can be seen within the literature on the political economies of scale, where changes in the scale of state regulation typically characterized as globalization are integral to processes of neoliberalization (Gough, 2004, p. 432; for an IPE engagement see Charnock, 2010). This is the result of multiple competing, contradictory, cooperative scales ranging from

the bodies of working people to the urban centres that concentrate and accumulate finance capital, to the space of the nation with its borders and laws and regulatory apparatuses. Difference and equalization, or at least some dialectic between these, is endemic in every cell, pore, and social body that capitalism produces.

(Mitchell, 2001, p. 58)

Our proposed scalar-relational approach therefore captures the ubiquity of space in analysis of every aspect of social existence, whilst permitting interrogation of the sites and loci of power and - importantly - the relationship between these different scales.

The utility of this scalar-relational approach for critical IPE is most apparent when attempting to demystify the agents of the inherently asymmetrical processes of globalization. We argue, however, that the difficulty which, inter alia, neo-Gramscian perspectives have in conceptualizing the social constitution of space is manifest in attempts to analyse the struggles between dominant social forces within the global restructuring of capitalism. We argue that there is an overestimation of the coherence and unity of these elites precisely because their embedded relationship with the national-domestic remains undertheorized.

This notion resonates when Robinson and Harris posit a disembedded transnational capitalist class operating at the 'transnational level', whose interests and identity are no longer contingent upon nationaldomestic politics (2000, p. 11-13). Conversely, we argue that so-called 'transnational' social forces remain simultaneously transnationally oriented and nationally embedded. ${ }^{3}$ This is because the socio-institutional configurations, and circuits of capital upon which their accumulation strategies depend, are necessarily rooted in established conditions in specific 'national' and local contexts, in spite of the 'transnational' scale of operations (Macartney, 2009). Accounts of transnational capitalist classes in critical IPE tend to privilege the transnational at the expense of the national, precisely because of the methodological focus 


\section{PROOF}

on political-economic agency. As we noted above, analysis therefore centres on either national or transnational forms of agency in a way that invariably marginalizes the significance of the other. As we explain, transnationalization concerns the reorganization and the reconstitution of capitalist social relations. Yet despite the mobility of capital, experienced most acutely in particular circuits and by particular fractions, no matter how footloose finance capital might be, it must 'land' in production somewhere. Capital remains embedded in territorially located institutional arrangements and infrastructures, as well as in particular social configurations such as class alliances and localized labour markets (Harvey, 1985, p. 146-157) that are not solely reducible to the national (Charnock, 2010; Macartney, 2009; Shields, 2008; Wilson, forthcoming).

Our scalar-relational approach to the transnational contends that to speak of a transnational capitalist class and transnational hegemonic project, pace van Apeldoorn, (2002) risks reifying their agency. This move also risks obfuscating political spaces for counter-hegemonic resistance by reproducing myths of the ubiquity and salience of both these agents and their associated ideological apparatuses. Instead, the concept of transnationally oriented fractions of capital emphasizes - at once - their emergence from particular national-domestic conditions and yet their continued embeddedness therein. As the crisis of 200709 has revealed, national forms of resistance remain fruitful given the revelation that transnationally oriented finance does not simply exist externally to the nation state, with an elusive exogenous power over domestic politics, but across a variety of scales simultaneously. Whilst this is no doubt also the argument of critical IPE, it is precluded by an analysis of Political and Economic relations to which Spatial relations are added only before the final stir.

\section{Conclusions and beginnings?}

This chapter has argued that both orthodox IPE and critical IPE have a problem with space. In effect, both sets of accounts have tended to focus on the relationship of the political to the economic, typified by the national/international trope, with space added to the mix later as the internationalization of the political economy became increasingly apparent. Paradoxically, in its critique of the orthodoxy, critical IPE has primarily addressed the internal relations of the state and the market through an emphasis on historicizing the emergence of social forces, yet it remains wedded - albeit implicitly - to the assumptions of the orthodoxy in relation to space. Just as Susan Strange (1970) highlighted 
the mutual neglect of the study of international politics to the study of international economics, critical IPE needs to reconsider the issue of space. Put differently, we suggest that the difficulties in conceptualizing spatial relations are related to more fundamental problems in understanding the historical and social under globalization, and that the counter-hegemonic project of critical IPE is hamstrung by its inability to theorize space. This chapter has argued that both mainstream accounts and Coxian-inspired neo-Gramscian readings therefore fail to comprehend the internal relations of these processes.

In contrast, we emphasize the dynamic, mutually constitutive processes of historical, social and spatial change as internally related phenomena, since 'tendencies towards differentiation and universalization or equalization, emanate side by side in the belly of capitalism' (Smith, 1984, p. 90). Spaces are not simply a platform for the unfolding of history; space is simultaneously precondition, mediator and outcome of this highly conflictual process. From here we suggest the scalar-relational understanding of the transnational such that, for example, the state is perceived as both site for and outcome of sociopolitical struggles perpetually unfolding on overlapping and potentially contradictory forms of territorial organization. The focal points and conceptual categories employed by critical IPE risk precluding an analysis of the codependence of these components to the actual historical process. Finally, in exploring current usage of the transnational we emphasize the importance of our conclusions for de-reifying agents of globalization, and make an initial step in contributing to counterhegemonic endeavours. This suggests, however, the need to overcome the persistent and deep divisions within critical IPE that preclude a more holistic critique of relations of domination, inequality and injustice.

\section{Notes}

1. It is worthwhile noting the proposition that prior to this epochal moment the world was not composed of territorially discrete units that characterize the Westphalian state system (Lacher, 2003).

2. In more recent work Gill has turned to Polanyi to account for these changes (see Bruff, this volume).

3. In our view, whilst this is also the intended argument of a historical, materialist critical IPE more generally, it remains highly problematic given the implicit assumptions about space which emerge under scrutiny. 
QUERIES TO BE ANSWERED BY AUTHOR (SEE MARGINAL MARKS)

IMPORTANT NOTE: Please mark your corrections and answer to these queries directly onto the proof at the relevant place. Do NOT mark your corrections on this query sheet.

Chapter 2

\begin{tabular}{|c|c|c|}
\hline Query No. & Page No. & Query \\
\hline AQ1 & 27 & $\begin{array}{l}\text { The response to the query 'Do you } \\
\text { mean "theories" here?' is not clear. } \\
\text { Please clarify whether we need to } \\
\text { replace 'theories' with 'Its the different } \\
\text { theories and writers'. }\end{array}$ \\
\hline AQ2 & 29 & $\begin{array}{l}\text { The response to the query 'Not clear to } \\
\text { whom this refers' is not clear. Please } \\
\text { clarify whether we need to replace } \\
\text { 'their' with 'Keohane \& Milner, but } \\
\text { realism and liberalism in general'. }\end{array}$ \\
\hline
\end{tabular}

